\section{Negative salience in impression of character: Effects of new information on established relationships}

\author{
MARJORIE H. RICHEY, St. Louis University, St. Louis, Mo. 63103 \\ HAROLD W. RICHEY, University of Missouri, St. Louis, Mo. 63121 \\ and \\ GREGORY THIEMAN, St. Louis University, St. Louis, Mo. 63103
}

College students were given hypothetical information that was inconsistent with their prior opinions of a liked or disliked acquaintance and asked to imagine its effect on their evaluation of his character. Sixty-four percent of those given incompatible negative information and $39 \%$ of those given incompatible positive information rejected this information until specifically instructed to assume its authenticity. Original character ratings subsequently changed more in response to negative information than to positive. Effects of communications tended to diminish within 1 week but remained significant. Less reversion toward original opinions occurred in delayed ratings if the acquaintance's alleged behavior had personal implications for $\mathrm{S}$.

A study by Richey, McClelland, \& Shimkunas (1967) reported evidence of a delayed disproportionate influence of negative information on impressions of character. When instances of both reprehensible and commendable behavior were reported to Ss about a previously unknown other, the negative information had a greater weight in overall impressions measured after an interval of 1 week. This result has been replicated in studies varying stimulus extremeness (Cusumano \& Richey, 1970), sex of perceiver and other (Richey \& Dwyer, 1970), relative amounts of positive and negative information (Fortin, 1968), and medium of presentation (videotape dramatization) of the behaviors (Sheehan, 1972).

While the finding seems to be reliable for the materials and procedures used, questions remain concerning its generalizability. For example, does it apply only to first impressions, or would judgments of prior acquaintances, toward whom definite sentiments already exist, also be more affected by negative information? Triandis (1971, p. 186), citing the study by Richey et al (1967), suggested that the negative bias may be learned first in connection with judgments of acquaintances and later generalized to impressions of strangers.

It would seem reasonable to expect that judgments of familiar persons, whether liked or disliked, would be more resistant to change than judgments of hypothetical strangers. Given this expected resistance, however, the question of present interest is whether new negative information will still have a greater impact than new positive information when each opposes a conflicting prior attitude.

Psychon. Sci., 1972, Vol. 28 (2) for both this initial period and a later follow-up session, and (2) had indicated moderate to strong feelings of liking or disliking toward the acquaintance. Those indicating only mild feelings (ratings of 3 or 5 ; see procedure) were discarded, except for three randomly selected individuals giving ratings of 3,3 , and 5 , who were retained to equate cell numbers.

\section{DESIGN}

The design was a 2 by 2 by 2 by 2 factorial with repeated measures on the fourth factor. Independent variables were sex of perceiver, incongruent condition (positive initial attitude plus negative information vs negative initial attitude plus positive information), personal relevance of the acquaintance's behavior (whether it affected $S$ himself or only other persons), and trial (immediately after the incongruent information or 7 days later). The dependent variable was amount of change from pretest to posttests in character ratings of the acquaintance.

While direct attempts to study this question would involve obvious methodological problems, there has been at least one attempt to explore a related question. Pastore (1960) asked Ss to rate the possibility that a person who possessed liked traits could change into one who possessed disliked traits, and vice versa. The first possibility was judged to be more likely. The present study attempts to go a step further, by testing the effect on a specific relationship of specific incongruent information about the other person. As the nearest practicable approximation to a naturalistic situation, the method adopted for this study used a combination of "real-life" and role-playing conditions. An actual acquaintance was the stimulus person, but the $S$ was asked to imagine how certain hypothetical information would affect his perception of this real acquaintance. This method was selected as the most feasible way to attempt control of valence, amount, and kind of new information intended to change pretest opinions. Standard positive and negative behavior descriptions were introduced into the context of real-life relationships of known valence, and their relative impact was assessed in terms of the attitudinal changes which Ss believed they would experience.

\section{SUBJECTS}

The Ss were 88 junior-college students, 44 males and 44 females, tested during regular class periods. In a first session, all volunteering members of the classes involved were asked to describe and rate either a person whom they definitely liked or one whom they definitely disliked. Within sexes, assignment to treatments was at random. Ss were retained in the study proper only if they (1) were present

\section{PROCEDURE}

In the first session, Ss were provided with these written instructions:

"Among your acquaintances (not relatives) there is probably at least one man who fits all the following specifications: $30-40$ years old, married, father of one or more children, employed in a business in which he has both superiors and subordinates.

"From among the men you know who have these characteristics, please think of one man whom you definitely like [dislike]. Without giving his name or other identifying information (e.g., the company he works for), please write in the space below a brief description of his personality. Spend about five minutes on the description."

The particular specifications required were selected because they apply to the stimulus person described in standardized paragraphs used in earlier studies. Ss were asked to describe the acquaintance in their own words in the expectation that active recall would help to evoke whatever feelings they had toward the acquaintance and thus stimulate their greater involvement in the procedures. After writing the descriptions, they were instructed to rate the individual they had described on 7-point ordinal scales for (1) the degree to which they liked or disliked him; and (2) their impression of his character. The mean like-dislike rating for initially liked others was 1.50 ; for disliked others, it was 6.68 . When the respective deviations of these means from the neutral point on the scale (4.0) are compared, results show that the initially positive attitudes did not differ in extremeness from the initially 
Table 1

Means and Standard Deviations of Change Scores

\begin{tabular}{|c|c|c|c|c|}
\hline \multirow[b]{3}{*}{ Group } & \multicolumn{2}{|c|}{ Trial 1} & \multicolumn{2}{|c|}{ Trial 2} \\
\hline & \multicolumn{2}{|c|}{$\begin{array}{c}\text { (Change from } \\
\text { Rating } 1 \text { to } \\
\text { Rating } 2)^{*}\end{array}$} & \multicolumn{2}{|c|}{$\begin{array}{c}\text { (Change from } \\
\text { Rating } 1 \text { to } \\
\text { Rating } 3)^{*}\end{array}$} \\
\hline & Mean & $S D$ & Mean & SD \\
\hline DPS-M十 & 1.73 & 1.05 & 1.55 & 1.23 \\
\hline DPS-F & 1. 27 & 2.00 & 1.73 & 2.34 \\
\hline $\mathrm{DPO}-\mathrm{M}$ & 2.09 & 1.73 & 1.09 & 1.24 \\
\hline $\mathrm{DPO} \cdot \mathrm{F}$ & 1.73 & 1.48 & .64 & .88 \\
\hline LNS-11 & 3.36 & 1.72 & 2.73 & 2.18 \\
\hline LNS-F & 2.64 & 1.23 & 2.36 & 1.49 \\
\hline LNO-M & 3.64 & 1.15 & 2.73 & 1.54 \\
\hline $\mathrm{LNO}-\mathrm{F}$ & 2.27 & 1.71 & 1.82 & 1.64 \\
\hline
\end{tabular}

*Sign disregarded

$\div$ First letter refers to initial attitude toward acquaintance $(D=$ dislike. $L=$ like): second letter to volence of incongruent information $(F=$ positive. $\mathrm{N}=$ negative $)$ : third letter to object of acquaintance's behatior $1 O=$ others. $j=$ self, i.e., $S$ himself); fourth letter to sex of $S$.

negative $(t=.23, \mathrm{df}=86)$. The mean rating for character given the acquaintance by the disliking group was 2.25 (negative); for the liking group, it was 5.93 (positive). When these means are compared for extremeness, there is again no significant difference $\quad(t=.12$ $\mathrm{df}=86$ ). The liking and disliking groups were therefore matched for intensity of initial sentiment toward the stimulus person, as well as for the polarity of the character ratings they originally assigned him. The liking and character ratings were almost always consonant. Only three Ss (females) gave negative character ratings to men they liked; no $S$ gave a positive character rating to a disliked acquaintance.

Following the initial ratings, $\mathrm{S}$ was given hypothetical information which was incompatible with his previously stated attitudes toward the acquaintance, i.e., negative if $S$ liked him and had given him a good character rating, positive if $\mathrm{S}$ disliked him and had given him a poor character rating. The positive and negative blocks of information used here had been developed for a previous study (Richey et al, 1967) in which they received favorability ratings that were equally extreme. The positive paragraph used here (from Form II in the original study) had received a mean rating of 5.88 and the negative (from Form I) a mean rating of 1.88. The two means did not differ in the degree of their deviations from the scale midpoint, $4.0(t=.55, \mathrm{df}=30)$. These particular paragraphs were chosen for this study because the content of each represents an inversion of the other, insofar as it was possible to write inverted content and retain the desired polarity (see Richey et al, 1967). The choice of paragraphs describing opposite reactions in the same interpersonal situations was intended to equate for dimensionality of the presumably out-of-character behaviors reported to the $\mathrm{Ss}$ about their acquaintances. The following instructions were given before the paragraphs were presented: "The next step in the study requires you to use your imagination to predict how you would feel in a hypothetical situation. Suppose that you were to receive the following information about the same person whom you described on page 1 , whom we will designate here as ' $\mathrm{X}$.' " In the treatment groups in which behaviors were to have personal relevance for $S$ himself, the following sentence was added. "Imagine that you, yourself, are one of his co-workers."

The paragraphs are presented below:

Positive
"Although $\mathrm{X}$ would have been happy to be rid of a subordinate whom he perceived as a potential rival, he gave good reports of this man's work to their superiors and gave him a deserved salary increase without which the subordinate eventually would have quit. He never accepts credit for ideas of more creative colleagues and subordinates in his department but always gives full public recognition to the originator, even when he could pretend the ideas were his without the originator's knowing it. At a party which he and his wife attend together, he appears to enjoy her company and passes up the opportunity to flirt with younger women who find him interesting. He makes time for activities with his children even when he is tired and pressured by other demands. He contributes to the financial support of his elderly parents, who live on a meager pension, although it means that he must forego some luxuries enjoyed by others in comparable positions."

\section{Negative}

"When $\mathrm{X}$ wanted to get rid of a subordinate whom he perceived as a potential rival, he did not give the subordinate a merited salary increase, thereby eventually causing the subordinate to resign. He sometimes utilizes the ideas of more creative colleagues and subordinates without giving them credit, acting as though he were the originator. At a party which he and his wife attend together, he tends to ignore her and flirt with any younger women who happen to be present. He has little time for activities with his children; when at home he is 'too tired.' He contributes nothing to the financial support of his elderly parents, who live on a meager pension, although he buys a new car for himself every year."

After reading the appropriate positive or negative paragraph, Ss were asked first to write what they thought their reactions to this information would be. As had been anticipated, many of them expressed some degree of incredulity, e.g., "I would have to say that the person telling me this was mistaken."' Such statements of disbelief were made by $64 \%$ of those with initially positive attitudes and by $39 \%$ of those with initially negative attitudes. The difference between groups is significant $\left(\chi^{2}=\mathbf{5} .50, \mathrm{df}=1\right.$, $\mathrm{p}<.05)$. The next instruction recognized that $S$ might, with good reason, be incredulous, but asked him nevertheless to make the assumption that the statements were true: "Imagine that you, yourself, had witnessed the behavior described and therefore know for certain that it happened." Ss were then asked to rate the character of the acquaintance again, basing their impressions on the new information as well as on their previous knowledge of $\mathrm{X}$. One week later, without advance notice, they were asked to respond to the rating scale a third time, still under instructions to imagine the new information to be accurate.

\section{RESULTS}

Summary statistics for the change scores are given in Table 1. Analysis of variance indicated a main effect for incongruent condition $(\mathrm{F}=14.13, \mathrm{df}=$ $1 / 80, p<.01$ ), a main effect for trial $(F=12.14, \mathrm{df}=1 / 80, \mathrm{p}<.01)$, and an interaction of Personal Relevance by Trial $(F=5.76, \mathrm{df}=1 / 80, \quad \mathrm{p}<.01)$. There were no main or interaction effects of sex of perceiver. The main effect for incongruent condition indicated that character ratings of persons who were initially liked (and whose characters were positively evaluated) changed more than character ratings of persons who were initially disliked. That is, the discrepant negative information had a greater effect than the discrepant positive. The trial effect reflected the fact that the change from initial attitude was greater on first exposure to the new information than it was a week later, when the ratings had begun to revert toward their earlier level. The Personal Relevance by Trial interaction was due to the fact that the effects of the personal relevance variable were reversed from Trial 1 to Trial 2. On the first postinformation trial, changes in character ratings tended to be greater when other people, rather than $\mathrm{S}$ himself, were the object of the acquaintance's actions. On the delayed trial, the difference scores tended to be greater for the "self" than for the "other" condition. 
The patterns of valence change over trials can be seen more clearly by comparisons of the ratings themselves rather than the change scores. Table 2 gives the mean ratings over trials for all treatments, sexes combined. A second analysis of variance, this time a 2 by 2 by 3 , with repeated measures on the last factor, was done on these raw data. Sex was eliminated as a factor, since it had had no effect on the change scores. The independent variables therefore were incongruent condition, personal relevance, and trial. There were three trials in this case, since the initial rating of the acquaintance, before the bogus information, was included along with the immediate and delayed postinformation trials. This analysis indicated a main effect for incongruent condition $(\mathrm{F}=13.39$, $\mathrm{df}=1 / 84, \mathrm{p}<.01$ ), a main effect for trial $(\mathrm{F}=8.85, \mathrm{df}=2 / 168, \mathrm{p}<.01)$, and an interaction of Incongruent Condition by Trial ( $F=108.09$, $\mathrm{df}=2 / 168, \mathrm{p}<.01$ ). There was also a trend toward a second-order interaction of Incongruent Condition by Personal Relevance by Trial $(\mathrm{F}=2.39, \mathrm{df}=2 / 168, \mathrm{p}<.10)$. The main and first-order interaction effects of incongruent condition were predictable in that the initial rating of the liked acquaintance was, by design, higher than that of the disliked acquaintance. The trial effect was due to the fact that the ratings overall were higher on Trial 1 than on Trial 2 $(\mathrm{t}=12.65, \mathrm{df}=87, \mathrm{p}<.01)$ or Trial 3 $(\mathrm{t}=9.63, \mathrm{df}=87, \mathrm{p}<.01)$. Analysis of simple effects of trial by the method described by Winer (1962) indicated that in each of the four treatment groups, the bogus information resulted in a significant $(\alpha=.05)$ change from initial rating of the acquaintance. The initially positive ratings became more negative and the initially. negative became more positive. During the following 7 days, three of the four treatment groups reverted toward their initial (preinformation) ratings, the DPO and LNO (those in which the acquaintance's behavior affected other people only) changing significantly from their Trial 2 levels. In the DPS (initial dislike, personally affected) group, the final rating was slightly (not significantly) higher than the second. In all groups, however, the final ratings remained significantly changed from those given on the initial preinformation trial.

\section{DISCUSSION}

The results are interpreted as

Table 2

Means and Standard Deviations of Character Ratings (Raw Scores)

\begin{tabular}{|c|c|c|c|c|c|c|}
\hline \multirow[b]{2}{*}{ Group } & \multicolumn{2}{|c|}{ Trial 1} & \multicolumn{2}{|c|}{ Trial 2} & \multicolumn{2}{|c|}{ Trial 3} \\
\hline & Mean & SD & Mean & SD & Mean & SD \\
\hline DPS* & 2.05 & .88 & 3.55 & 1.75 & 3.68 & 1.72 \\
\hline DPO & 2.45 & 1.03 & 4.36 & 1.64 & 3.32 & 1.52 \\
\hline LNS & 5.95 & $1.19^{\circ}$ & 2.95 & 1.15 & 3.41 & 1.56 \\
\hline LNO & 5.91 & 1.28 & 2.95 & 1.52 & 3.64 & 1.67 \\
\hline
\end{tabular}

* See Table I for interpretation of group designations.

supporting the hypothesis of negative bias in judgments of character: character ratings were more affected by incongruent negative information than by incongruent positive information, once the communications were accepted as valid. This finding, already obtained for the case where the stimulus person is a stranger, is generalized to the instance where he is a previous acquaintance toward whom $S$ already has a definite positive or negative attitude. Thus, Triandis (197.1) is apparently right in the speculation that negative information about acquaintances is also more powerful than positive. Whether this mechanism is first learned in connection with judgments of acquaintances and then generalized to strangers, as he hypothesizes, is a question not answered by the present study.

While opinions were initially more affected when persons other than $S$ were the targets of the acquaintance's actions, on the final trial, the change from original opinion was greater if $\mathbf{S}$ himself had been the target. The more permanent effect when one is personally concerned seems reasonable on the basis of both exchange theories and common observation. Several Ss even verbalized this difference, e.g., "I would lose a lot of respect for this man, but since I do not work for him and he hasn't hurt me personally, I don't think this would end our acquaintance."

Previous studies reporting negative bias in impression formation (Richey et al, 1967; Cusumano \& Richey, 1970 ) have also noted the incompatibility of the findings with simple averaging and simple summation theories of information integration. Comparisons of the ratings obtained in the present study with predictions of these theories is not feasible, because it would require knowledge of the number and valences of all pretest beliefs about the acquaintance. One implicit assumption of both simple averaging and simple summation theories, howver, is that information of either valence has the same weight in the total impression. The present findings are inconsistent with this assumption, since negative information had a greater impact than positive on conflicting prior impressions of matched polarity.

There is an optimistic note in the present findings which may soften possible inferences about the loyalty of friends: Opinions concerning acquaintances, especially favored ones, are apparently not easy to change. Most (64\%) of the Ss judging friends indicated, some of them rather indignantly, that they would not believe such negative reports about their friends. They made their reappraisals only when pushed by the instructions to imagine that the evidence was undeniable. Perhaps Cassius was right: "A friendly eye could never see such faults."

REFERENCES

CUSUMANO, D. R., \& RICHEY, $M$ : $H$. Negative salience * in impressions of character: Effects of extremeness of stimulus information. Psychonomic Science, $1970,20,81-83$.

FORTIN, R. J. Valence and quantity of opposing information in impression formation. Unpublished MA thesis, St. Louis University, St. Louis, Mo., 1969 .

PASTORE, N. A note on changing toward liked and disliked persons. Journal of Social Psychology, 1960, 52, 173-175.

RICHEY, M. H., \& DWY ER, J. D. Negative solience in impressions of character: Sex differences. Psychonomic Science, 1970. 20, 77-79.

RICHEY, M. H., MCCLELLAND, L., \& SHIMKUNAS, A. M. Relative influence of positive and negative information in impression formation and persistence. Journal of Personality \& Social Psychology, 1967, 6, 322-327.

SHEEHAN, M. $R$. The relative salience of negative information in life-like situations. Unpublished doctoral dissertation, St. Louis University. St. Louis, Mo., 1972.

TRIANDIS, H. C. Attitude and attitude change. New York: Wiley, 1971.

WINER, B. J. Statistical principles in experimental design. New York: McGraw-Hill, 1962. 